\title{
Comparison of the effect of milk and pistachio (pistacia vera) snacks consumption on satiety status, body fat percent, and macronutrient intake in overweight or obese women: A randomized controlled trial
}

\author{
Majid Karandish ${ }^{1}$, leila sheikhi ${ }^{1}$, Mahmood Latifi ${ }^{1}$, and Iran Davoudi ${ }^{2}$ \\ ${ }^{1}$ Ahvaz Jondishapour University of Medical Sciences \\ ${ }^{2}$ Shahid Chamran University of Ahvaz
}

September 11, 2020

\begin{abstract}
Aim: The aim of this study was to identified the effect of consumption of milk and pistachio as snacks on satiety, body fat percent, and macronutrient intake in overweight or obese women. Methods: In this randomized cross-over trial, sixty overweight and obese women with mean age of $24.42 \pm 4.2$ years participated. Each Intervention lasted two one-month periods with a 6-day washout period. A visual analogue scale was used to score satiety. To calculate energy intake(macronutrient), a food record was obtained. Body fat percentage was calculated using the Deurenberg formula. Results: At the end of the study, there was not any statistical difference in energy intake at each snack groups (p-value>0.05). Body fat percent for women in the milk group significantly decreased $(\mathrm{p}$-value $=0.001)$. There was not any statistical difference in the area under the curve between pistachio and milk snack groups $(226.13 \pm 54.5$ and $225.16 \pm 47.48$, respectively, p-value=0.930). Conclusion: The consumption of pistachio and milk as a daily mid-morning snack for a month has a similar effect on the maintenance of the satiety status in obese and overweight people but it doesn't have any beneficial effects on calorie intake. Keyword: satiety, pistachio, milk What's known? A satiety control strategy is a novel method for achieving and maintaining an optimal body weight. Although snacks consumed has a significant role in satiety status, there isn't any specific guidance for snacking choices. What's new? Presently, the evidence with regarding association between kind of snack and satiety results are inconsistent. As our finding, the functional food and healthy snacks consumed can a key role in satiety status.
\end{abstract}

\section{Hosted file}

manuscript.docx available at https://authorea.com/users/358276/articles/480604-comparisonof-the-effect-of-milk-and-pistachio-pistacia-vera-snacks-consumption-on-satiety-statusbody-fat-percent-and-macronutrient-intake-in-overweight-or-obese-women-a-randomizedcontrolled-trial 